Original slrticleg.

\section{HEMATURIA DUE TO THE BILHARZIA HEMATOBIA, WITH THE REPORT OF A CASE.*} roeon to the Genito-Urinary Department, Boston Dispensary; Assistant Surgeon to St. Elizabeth's Hospital.

THE disease forming the subject of this paper being a very uncommon one in this country, the writer thought that a short description of the etiology, pathology, literature, etc., of the condition would be of interest. The following is therefore submitted:

Bilharzia disease (or as it is variously known as bilharziosis, endemic hematuria, blood water of the Boers, and hématurie bilharzienne) is the name given to the lesions produced in the human body by an animal parasite, the distoma hematobia, or, as it is more commonly known, the Bilharzia hematobia, after its discoverer, Professor Bilharz of Cairo.

The occurrence of hematuria and urinary calculus has long been recognized in Egypt, and we have records to that effect as far back as the fifteenth century. Hematuria was also said to have been common among the French troops in Egypt during the occupation by Napoleon in 1798. ${ }^{1}$ It was not until 1851, however, that these phenomena were properly explained, when Professor Bilharz discovered and described the parasite, he being the first to recognize its clinical importance.

The parasite is a fluke or trematoid worm with distinct sexes. The male is described as being white and cylindrical in form (Manson), ${ }^{2}$ measuring from 11 to $15 \mathrm{~mm}$. in length and $1 \mathrm{~mm}$. in breadth. It has an oral and ventral sucker placed close together. The cylindrical appearance is produced by the ventral infolding of the two sides of what would otherwise be a flat body. By this infolding a gynecophoric canal is formed in which the female is received during coitus.

The female is somewhat darker and considerably longer than the male $(20 \mathrm{~mm}$.), the body being filiform. The anterior and posterior ends remain free while the middle section is contained in the gynecophoric canal of the male. The genital opening of the sexes face each other and are placed immediately posterior to the ventral sucker. ${ }^{2}$

The eggs are oval in form and about $0.16 \mathrm{~mm}$. long by $0.06 \mathrm{~mm}$. in breadth, although they vary somewhat in size. They have a transparent envelope or shell with a distinct spine, generally at one end; in some cases it is lateral (see cut). The ova with the lateral spines occur only rarely in the urine. $\dagger$ In the reported case all the ova seen had terminal spines. Within the ovum is seen the embryo; it has a distinct border of its own and at times does not seem to fill the shell completely, especially at the ends, but is surrounded by fluid. The bulk of the embryo is made up of sarcode granules,

*Presented before the American Urological Society, Atlantic City, June 9, 1904.

t Duncan reports a case where ova with lateral spines were found in the urine (Clinical Society Transactions, London, Vol. 35, p. 187), but a canal may be traced from the beak into what seems to be a rudimentary stomach with a small glandular mass on each side of it. In the more mature ones the embryo may be seen to move the cephalic end with a jerky motion; with a high power the cilia may also be seen to move. By making gentle pressure on the cover glass the shell may be broken and the embryo observed while coming out. ${ }^{7}$ (In this manner the embryo for the accompanying cut was obtained and the process was most interesting to watch.) The shape of the embryo at rest may be said to be somewhat oval with a blunt pointed extremity which is the head. It is richly provided with cilia and is very motile when released. It changes its shape considerably when swimming, becoming elongated when in rapid motion. They soon die in urine (twenty-four hours), but may be kept alive in fresh water for a few days. The mature ova will hatch rapidly in fresh water. Dr. Perry of the Harvard Medical School endeavored to make them grow in various media but without success.

(For a more complete description of the worm and embryo the reader is referred to the special works on Entozoa, particularly a book by Braun, ${ }^{6}$ for a description of the worm, and to a paper in the Journal of Bacteriology and Pathology, by Dr. G. S. Brock of the Transvaal for a very minute and elaborate description of the anatomy of the embryo.) No more is known of the life history of the embryo. Sonsino ${ }^{17}$ at one time thought he had discovered the intermediate host in a small crustacean, which statement, I believe, he afterward contradicted. By analogy it may be assumed that the embryo is taken up by some intermediate host where it undergoes a certain stage of development, later becoming encysted, and, either free or with its host, is taken into man, where it develops to maturity.

Geographical Distribution..$^{8}$ - The parasite is found in almost all parts of Africa. In Egypt, especially in the region of the Lower Nile, it is most common, so common, in fact, that various observers estimate that about half of the native population of that region suffer from it. Greisinger and Bilharz report finding the worm 117 times out of 363 autopsies, and Sonsino 42 times in 91 autopsies. ${ }^{1}$ It is also endemic in the eastern part of Africa, Zanzibar, ${ }^{18}$ the Transvaal, the Cape, the Gold Coast, Tunis, Algeria, Natal and Abyssinia. Outside of Africa cases have been reported as occurring in Mauritius, Madagascar, Cyprus, Syria, India, ${ }^{10}$ Mecca and Penang. ${ }^{3}$ A case is also reported from the West Indies. ${ }^{3}$ The cases met with on the continent of Europe, in the British Isles and in the United States are probably imported ones with the possible exception of those occurring in the Middle West, which will be referred to later on.

Etiology. - The exact method of infection of the human species with the disease is not definitely known, as the life and development of distoma outside the body is entirely unknown. The two most probable avenues of infection are, however, first, that the embryo is carried into the 
system by drinking infected water, or possibly by eating shellfish or raw vegetables; second, by infection while bathing, through the skin or natural openings of the body. Both of these theories have their supporters and various arguments in their favor. Bilharz himself favoring the first method.

The most noteworthy fact with regard to infection through drinking water is that the people of the large cities, like Cairo and Alexandria, suffer very rarely in comparison with the country people who drink water from the pools and rivers while at work. It is said that Europeans escape the disease to a large degree because they are, as a rule, very careful about their drinking water. (Sonsino, Scheube. ${ }^{1}$ )

With regard to the infection during bathing, Dr. Brock ${ }^{4}$ says he is convinced that in the Transvaal at least many cases are infected in this way. He says in explanation of this that most cases occur in boys from six to sixteen years of age who bathe constantly in the rivers and ponds, sometimes spending the greater part of the day, in the water, while the Boer girls, who seldom bathe, ${ }^{1}$ are rarely affected, both being exposed to an equal danger from drinking water. So common is the hematuria among the Boer boys that the more ignorant of the natives believe the loss of blood to be physiological.

Dr. Allen believes that the long prepuce of boys favors infection through the urethra. Loose (Manson) has recently expressed the opinion that the ciliated embryo enters the body directly by perforation of the skin. ${ }^{11}$ It has been observed in Egypt that the natives who work in the fields up to their knees in water for a great part of the time are more liable to have the disease than those who do not follow agricultural pursuits. This might mean, however, that they are more exposed to the temptation of drinking bad water. It would seem that there is good foundation for the theory of infection while bathing, although it is always possible to swallow some water while so doing. In no case has a man been known to have transmitted the disease to his wife.

The period of incubation is difficult to determine; according to Brock ${ }^{4}$ it is four months.

Pathology. - Although the lesions in this disease are not entirely confined to the genito-urinary tract, this system, in a large majority of cases, is the one which suffers, and it is with this tract that the pathology has mainly to deal. The adult worm is found most often in the portal system, either in the main vein or some of its tributaries, the most common being those of the urinary apparatus and the rectum. They have been found, also, in the inferior vena cava and, rarely, free in the urinary passages. They may be in large numbers, Kartulas reporting a case in which three hundred were found. (Finding them most often in the portal system would seem to favor the idea that they were taken into the body by way of the stomach. Finding them in the systemic veins as well could be explained by the anastomosis between the mesenteric and the internal iliac through the hemorrhoidal branches.. The adult worm itself does not seem to cause any particular trouble, all the lesions being due to the deposit of the ova in the tissues. In whatever manner the worm gets into the circulation, at certain times they descend in pairs into the smaller branches of the aforementioned veins and the female deposits her eggs in great numbers. They finally rupture the vein, escaping into the surrounding tissue and there form the nuclei for inflammatory changes. These collections of ova and the subsequent changes which they induce were called "Bilharzial Infarctions" by Bilharz. When one of these infarcts ruptures into the urinary passages or the rectum a hemorrhage of greater or less extent occurs, which gives rise to the hematuria so characteristic of the disease, and to the finding of large numbers of the ova in the urine and feces.

Both clinically and post-mortem, the urinary bladder is found to be most often affected. Milton $^{9}$ found this organ diseased in $64 \%$ of a series of 930 cases, the lesions being principally in the sub-mucous and mucous coats. They consist in the milder cases of congested and ecchymosed patches, varying in size from one-fourth to onehalf inch in diameter, covered with mucus containing many ova. (In my case these patches could be very beautifully seen with the cystoscope). They are generally on the posterior part of the bladder. As the disease advances the lesions take the form of vegetations and excrescences which become encrusted with urinary salts and must not be mistaken for calculi with the stone searcher. The capacity of the organ becomes reduced, its walls thickened and the outgrowths may fill the entire viscus; in some cases, however, the bladder is dilated. These changes taking place as well in the ureters and pelves of the kidneys, together with the formation of urinary calculi, which is very common in the disease, give rise to all manner of urinary lesions, among the more serious of which are dilated ureter, hydroand pyo-nephrosis, cystic kidney, renal abscess and nephritis. Abscess and sinus formations are also quite common in the advanced cases. Urinary fistulæ are most commonly scrotal, perineal or in the glans, more rarely in the thigh, buttock or suprapubic regions. The seminal vesicles and the prostate are often affected. The lesions in the rectum are similar to those in the bladder, generally taking the form of excrescences.

The ova have been found in other parts of the body, $¥$ in the liver,, 5 giving a form of cirrhosis; in the lungs, giving rise at times to hemoptysis. They are said to cause certain skin lesions, and have been found in gallstones. The female genitals are occasionally affected. The disease occurs on the labia majora in the form of excrescences; in the uterus, in the form of polypi protruding from the cervix. ${ }^{9}$ According to Milton, disease of the uterus is not found without disease of the vulva. There is generally present a sero-sanguinous discharge containing ova.

$\ddagger$ A curious case is reported by Cureton and Webb (Lancet, 1899 , Vol. I, p. 156) where at a post-mortem they found the appendix enlarged and nodular; on section the nodules showed the presence of cause. 
Carcinoma and adenoma have been reported following the disease (Kartulis).

The Blood. - Bilharzia disease, in common with other parasitic diseases, presents some changes in the blood, the most conspicuous one being the altered proportion of eosinophiles. Coles ${ }^{12}$ was the first to suggest this condition, and he reports a case with $20 \%$ of eosinophiles. Russel ${ }^{13}$ follows with another case, the average of three examinations being $29 \%$. The next case is reported by Manson ${ }^{3}$ with $12 \%$. Then follows a very careful study of fifty consecutive cases by Douglas and Hardy ${ }^{14}$ of the white cells found in the blood and urine. These results are, first, that all cases seem to have a leucocytosis, and, second, that in all cases but one there was an eosinophilia, the average being $16.48 \%$. (The highest count being $40 \%$ and the lowest $1.3 \%$.) With regard to the urine, they found the number of ova and the amount of blood varied greatly in different cases, and on different days in the same case, that there were many leucocytes in the urinary sediment, and that the greater number of these were eosinophiles. $\$$ (This last observation is true of the case herein reported.) Balfour ${ }^{15}$ reports three cases with an average of $16.8 \%, \mathrm{Pool}^{28}$ a case of $9.5 \%$, and the writer a case with $8.4 \%$. This makes a series of fifty-eight cases, in all but one of which the eosinophiles were increased in number. The average of the eight odd cases is $16.34 \%$, which is practically the same as the average of $16.48 \%$ for the fifty. In most of the cases the increase seemed to be at the expense of the polymorphonuclears. It would seem that this series of cases is large enough to justify the statement that eosinophilia is the rule in Bilharzia disease.

Diagnosis and symptoms. - The diagnosis is absolutely established by finding the ova of the parasite in the urine or feces of the patient, or in calculi or masses of tissue which have been removed. After once seen they are easy of recognition.

The most constant and characteristic symptom of the disease is hematuria. When there is a good deal of hemorrhage the urine is entirely bloody, but generally the blood is confined to the last few drops voided, being due to the rupture of some of the infarcted areas by the final contraction of the bladder. The urine, in a moderate case on being passed, is generally slightly turbid (may be blood-tinted) and contains shreds resembling those of a mild urethero-cystitis. The sediment settles rather quickly leaving a normal looking urine. In the sediment are blood, pus and the ova, together with epithelial cells and urinary crystals, mostly uric acid and calcic oxalate. The reaction is acid at first and there may be a slight trace of albumin.

In the early days of the disease, and in light cases, there is no pain, in fact many cases have no other symptom but hematuria, which may be constant, intermittent, or so slight as to be detected only by the aid of a microscope. The hematuria is almost always made worse by exercise.

\$ This may also be due to the fact that the eosinophiles are found increased infvarious inflammations of the lower genito-urinary tract: as_cystitis, prostatitis, etc. (Cabot.)
As the case progresses signs of inflammation of the urinary tract appear, the urine containing more mucus, blood and pus, and micturition becoming more frequent, itching or tickling at first, then burning, and later on painful, especially if small clots of blood or calculi have formed. Acute retention occasionally takes place from a clot or stone blocking the urethra. There may be attacks of renal colic from the same conditions in the ureters. In the more advanced stages of the disease the bladder becomes the site of vegetations and calculi are formed. Urinary fistula and abscess formation are common. The seminal vesicle and prostate are often involved, the semen containing blood and ova in the former condition. In involvement of the prostate the urinary symptoms are increased, and the gland, by rectum, may be felt to be enlarged.

The symptoms of invasion of the rectum are straining and frequency of defecation with the passage of blood accompanied by tenesmus, later prolapse of the mucous membrane and the formation of the characteristic vegetations.

As a rule death occurs from anemia or exhaustion dependent upon long continued hemorrhages and frequent attacks of pain, or as a result of some grave urinary disorder ending in uremia or septic infection.

Prognosis. - The disease varies in intensity in different localities, being much more severe in Egypt than in the Transvaal. In the latter location the disease is largely confined to boys from six to sixteen years old, at which age the hematuria disappears and the patient believes himself well. Careful examination will generally, however, detect the ova and the patient may, a number of years later, suffer from stone. Although a number of cases never go beyond the hematuria, still the prognosis should be guarded, the disease itself not being so fatal as the chain of complications to which it may give rise. To show how light the disease may be Milton ${ }^{9}$ reports that in the examination of one hundred patients on the medical service in the Kasr-el-Aini Hospital, in Cairo, the ova were found in thirty-five, only two of whom complained of any symptoms. According to Brock, patients with the disease are not taken by Life Insurance companies. The life of the worm is known to be a long one, Dr. Hanford ${ }^{16}$ reporting a case where the patient was having an occasional hematuria eight years after infection, there being no re-infection.

The treatment of the condition is unfortunately most unsatisfactory, and must of necessity be confined to maintaining the general health, and treating the symptoms and complications which arise. The deep location of the parent worm rendering any anthelmintic treatment of no value. According to more recent writers the hematuria is best met with salol and methylene blue. The latter is said to cause the death of the embryo in a short time in cover glass preparations. It is given in $4 \mathrm{gr}$. doses three times a day. If there is irritation or smarting of micturition, copaiba, santal oil or benzoic acid are of decided value. Cystogen and urotropin are useful as 
urinary antiseptics. Male fern is recommended by Milton, and santonin ${ }^{18}$ by other observers. If the hematuria is severe or cystitis is present, the bladder may be washed out with some bland solution, as boric acid, weak nitrate of silver, or possibly a solution of adrenalin chloride $\mathbf{1 0}, \frac{1}{\delta} \overline{0} 0$ might prove of value. The solutions should be bland as the bladder is sensitive. Fistulæ and calculi are to be treated surgically. Milton advises litholapaxy for the latter when possible, as cutting operations are not particularly well borne. In the latter stage of the disease drainage of the bladder may become necessary. In the rectum, vegetations should be removed when possible. According to Milton, a solution of the chloride of zinc 1 to 40 will give relief as an application when the excrescences are too numerous for removal. The anemia is to be met with iron and the general hygiene looked after. The patient should be removed from the country to avoid re-infection.

Prophylaxis, is very much handicapped by the fact that the life history of the parasite is unknown. In infected districts, however, the drinking water supply should be above question, and if any doubt exists as to its purity the water should be boiled or filtered, and raw vegetables should be carefully washed. The urine and the feces of the patients should be rendered harmless.

Report of case. - J. B., twenty-four years of age, printer. Presented himself at the Urinary Clinic of the Boston Dispensary on March 2, 1904, with the following history: Personal history - One attack of gonorrhea five years ago, left testicle was then swollen Without any reason that he could give testicle swelled again last year. For the last three years he has passed blood every day, once or twice a day, at the end of micturition, varying from a couple to a number of drops. It occurs at no particular time of day. There is no frequency or smarting or any trouble with micturition.

Examination. - Well developed and nourished young man, a trifle pale, nothing abnormal found except left epididymis has a tender nodule in upper end Prostate normal. Left vesicle full, not tender Nothing felt in renal region. Urine, very small quantity, slightly turbid with few shreds. It was not examined at this visit. Patient was given cystogen, gr. v, three times a day. To return for further examination. (Tumor of the bladder was considered the probable diagnosis.) He came back in twelve days much improved as to the frequency of the hematuria. The urine was normal looking after a moderate flocculent sediment had settled. Examination. - Normal color acid; sp. gr., 1,025; albumen, slight trace; sediment: pus, blood, crystals of calcic oxalate, and a number of large oval bodies, some of which showed a jerky motion in one end. They were diagnosed as some kind of parasite, and on reading the subject up they were recognized as the ova of the Bilharzia.

On further questioning, the patient said that he had been in South Africa, in the British infantry, during the Boer war for eighteen months, and had had no trouble for a year, when one day at mess he felt a burning and itching in the perineum, and later frequency of micturition set in and he began to pass blood. $\mathrm{He}$ said that on several occasions he had drunk very foul water. On his next visit he was examined with a cystoscope, when the bladder showed a membranous cystitis; fragments of tissue could be seen waving from the bladder wall in the fluid (very like seaweed under water). There were also a number of small hemorrhagic areas mostly about the left ureter and posterior part of the bladder.

The day after the cystoscopy he passed more blood than usual. According to his statement he is better than he has been at any time during the trouble, sometimes seeing the blood only once a week or once in a few days. He has no other symptoms, except pain in the left epididymis (whether this is due to the same cause I cannot say, but think it not unlikely). He has had no treatment but cystogen and urotropin. Ten weeks after his first visit he passed a perfectly normal looking urine in which only a few ova could be found. He has occasional hematuria, which is made worse by exercise.

The blood examination by Dr. W. H. Smith, at 8 P.M. is:
Red's, 5,212,000 Whites, 4,400
(Differential count of 500 cells)
Polymorphonuclears . . . . . $45.6 \%$
Lymphocytes. . . . . . . . . . . $45.8 \%$
Eosinophiles . . . . . . . . . . $8.4 \%$
Mast cells . . . . . . . . . . $.2 \%$

No achromia, no variation in size, no glandular degeneration.

Three months after his first visit he sent for me early in the morning, his wife saying that he had suffered intense pain all night in the left back and loin. On reaching his house I found him completely relieved, he having passed a small, very sharp, uric acid calculus; no ova could be found as nuclei. The urine was normal.

The only reference to cases of the disease occurring in the United States, that the writer has been able to find, are briefly as follows: They are five in number, three being imported cases and two seem to have originated in this country. There is also a case reported where the condition was supposed to exist, but I do not think the djagnosis was correct.

The first case reported, by Dr. Booth of Sparta, Ill. ${ }^{10}$ in 1882 , is that of a young woman of twenty-eight. She had difficulty in micturition and had passed blood. He reports finding in the urine ova with spines, ciliated embryos and mature worms. The description is not good. There is no satisfactory etiology given. I can find no case reported where the adult worm had been found alive in urine, and it is only with extreme rarity that it is found in the urinary passages at all. It has, however, been found alive in masses of papillomatous tissue and in fibrous tissue lining urinary fistulæ, Madden reporting six such cases. ${ }^{32}$

The next case is reported by Dr. B. F. Curtis ${ }^{20}$ of New York, in 1896. He performed a suprapubic operation for a tumor of the bladder in a man of twenty-nine. The patient had served in the British Army in Egypt ten years before and had been subject to hematuria. The diagnosis in this case was made from microscopic examination of the tissue removed. The result was good.

The third case is reported first by Brooks ${ }^{23}$ in 1897, a month later by Sondern ${ }^{24}$ and referred to by Porter ${ }^{25}$ in the International Clinics. The patient had lived two years in Africa. His only symptom was the characteristic hematuria. 
HEMATURIA - O'NEIL.

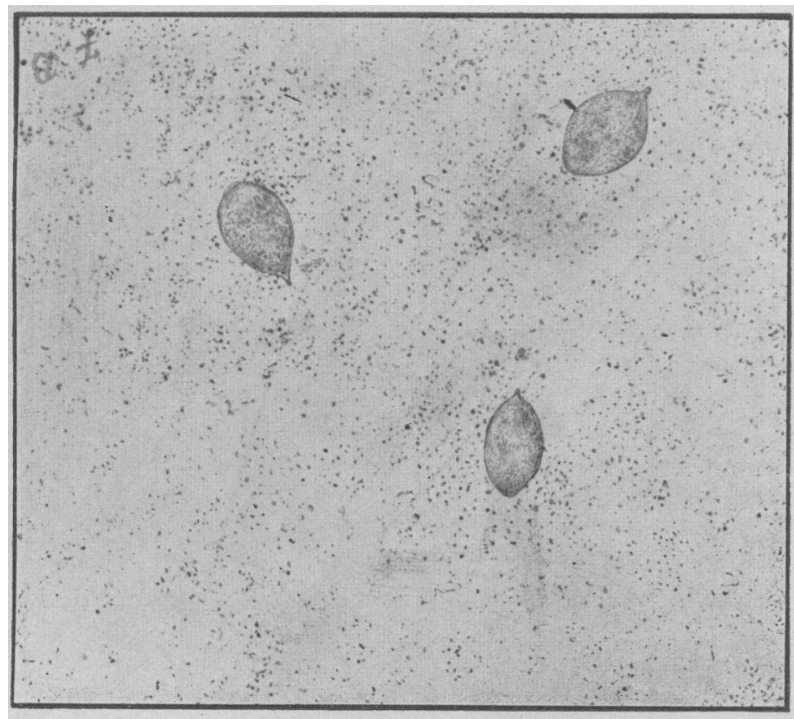

FIg. 1. (Leitz oc. 4, obj. 3.) Urinary sediment showing ova. Low power.

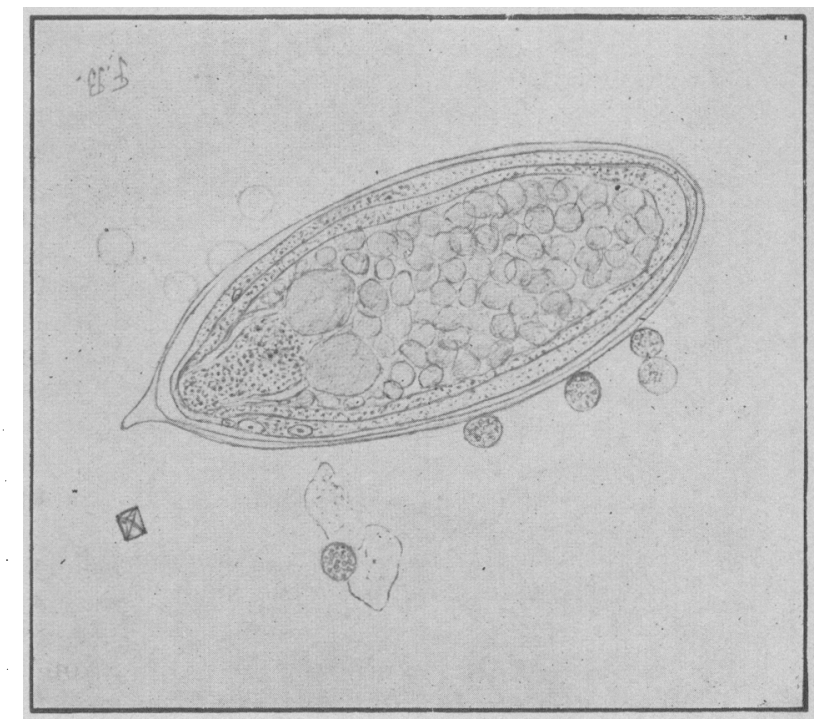

Fig. 3. (Zeiss oc. 6, obj. $2 \mathrm{~mm}$ ) Ovum. High power.

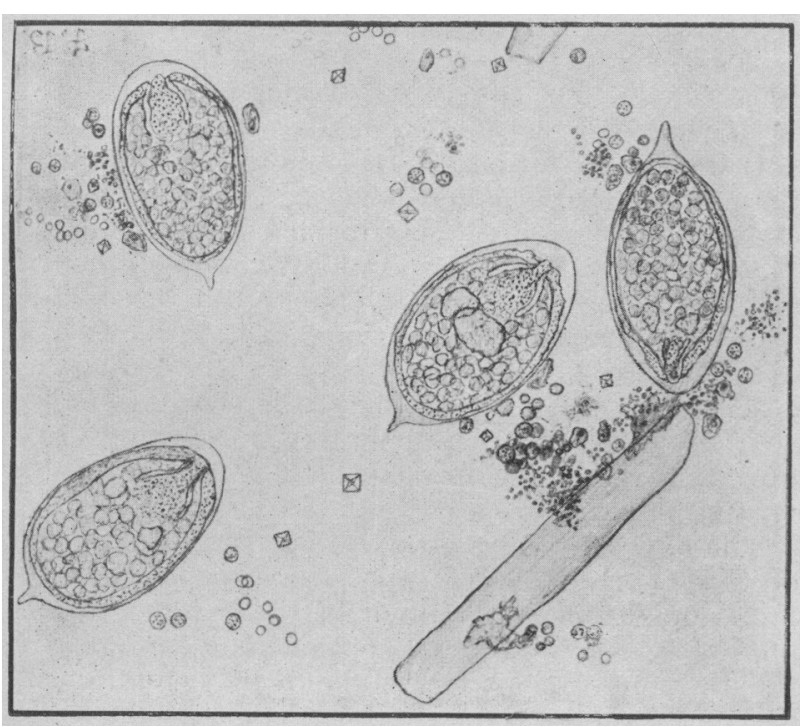

Fie. 2. (Zeiss oc. 4, obj. $8 \mathrm{~mm}$.) Note size of ova compared with other elements in sediment, also terminal spines.

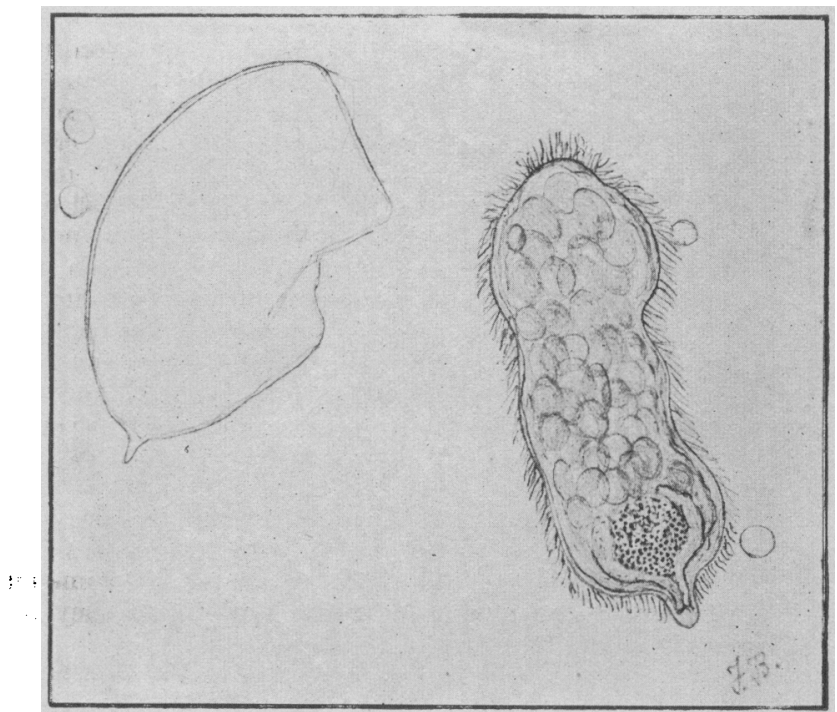

Fig. 4. (Leitz oc. 4, obj. 1-12.) Free swimming embryo showing cilia, also broken envelope. 
The next curious case was reported in February, 1900, by Dr. Walker ${ }^{21}$ of Evansville, Ind., his patient being a woman of twenty-eight, whose home was not far from the place where Dr. Booth's patient lived. She had suffered from severe pain in the bladder and the left side with hematuria. She also had occasional discharge of fluid from some cavity connecting with the bladder. This fluid was found to contain the ova and embryos of the parasite.

This case was again recently reported by Drs. T. N. and H. N. Rafferty of Robinson, Ill., who had her under observation from April, 1900, to September, $1901 .^{33}$ The patient was heard from not long ago and was still having the same trouble.

In June, 1900, Dr. Lewis ${ }^{22}$ of Mt. Carmel, Ind., referred to the following case as one of Bilharzia disease: The patient is a woman thirty-two years of age. She had painful and frequent micturition for some time. The urine contained much pus and a number of bright red very motile worms about one-sixth of an inch long. Towards evening she passed large numbers of them, they sometimes coming away in clumps of twenty or thirty. The bladder was indurated and tender. Although some of the symptoms are suggestive, no mention is made of finding the ova, and the description of the worm is certainly not characteristic. The only point in the etiology is that the patient used to eat largely of some imported figs known as Turkish. The case is probably not one of Bilharzia disease. $\|$

The last case is reported by Dr. Pool ${ }^{26}$ of New York, in April, 1903, and is that of a young Algerian, thirty years of age, who had visited some of the infected countries and presented the characteristic hematuria. As cases of this kind will undoubtedly occur from time to time in this country their correct diagnosis is of importance, and the writer suggests that a careful search be made for the ova of the parasite in any case suffering from hematuria, calculus or urinary fistulæ who has been a resident in or a visitor to the infected countries.

The literature of the condition is quite extensive, the writer having looked over from fortyfive to fifty different articles and reports of cases, most of them naturally being in foreign publications. Besides the two articles already referred to, those interested in the subject will find good accounts of the disease in the "Diseases of Warm Countries," by Scheube ${ }^{1}$ (which has an excellent bibliography), an article by Guillemard, in Allbutt's " System of Medicine," ${ }^{27}$ and one by Kartulas. ${ }^{28}$ Among the latest publications are three full lectures by Milton of Cairo, in the Journal of Tropical Medicine, ${ }^{29}$ an article by Wallace in the Scottish Medical Journal, ${ }^{30}$ and one by Lelean, in the Transactions of the Medical Society of London. ${ }^{31}$

The excellent drawings accompanying this article were made from fresh specimens by Miss Byrnes of the Harvard Medical School.

BIBLIOGRAPHY.

1 Soheube: Diseases of Warm Countries.

2 Manson: Tropical Diseases.

3 Manson: British Medical Journal, 1902, v. ii, p. 1894.

II The Distoma heterophyes is a small red worm.
${ }^{4}$ Brock: G. S. Journal of Pathology and Bacteriology, v. ii, 1893-94, p. 52 .

${ }^{5}$ Symmers, W. St. C.: Journal of Pathology and Bacteriology, v. ix, December, 1903

6 Braun, Max: Die Thierischen Parasiten des Menschen.

p. 420 .

8 Clemow: The Geography of Disease.

Milton: Lancet, 1903, v. i, p. 866

10 Powell: British Medical Journal, 1903, v. i, pp. 490-772.

11 Loose: British Medical Journal, 1903, v, i, pp, 262-789.

12 Coles: British Medical Journal, 1903, v. i, pp. 1137, May, 1902.

13 Russel: Lancet, December, 1902, v. ii, pp. 1540

14 Douglas and Hardy: Lancet, October, 1903, v. ii, p. 1009.

15 Balfour: Lancet, December, 1903 , v. ii, p. 1649 .

${ }_{16}$ Hanford: Lancet, Dec. 16, 1893.

17 Sonsino: Lancet, Sept. 9, 1893, p. 621

18 Petrie: British Medical Journal, 1903, v. ii, p. 133

19 Booth, D. S.: Western Medical Reporter, 1903, v. iv, No. 3 882, March 15

20 Curtis, B. F.: Annals of Surgery, v. xxiii, p. 56, Oct. 23, 1895 900

22 Lewis, R. F.: New York Medical Journal, June 30, 1900.

23 Brooks, H. T.: New York Medical Record, April 3, 1897.

${ }^{24}$ Sondern, F, E.: New York Medical News, May 1, 1897. 897

P.: International Clinic, Philadelphia, v. iii, p. 124, ${ }_{26}$ Pool, E. H.: Proceedings of the New York Pathological Society, April, 1903.

27 Guillemard: Allbutt's System of Medicine, New York, 1897, v. ii, p. 1091 . p. ${ }_{29}$ Milton: Journal of Tropical Medicine, 1902, v. v, p. 165, 191, 200,213 .

${ }^{30}$ Wallace: Scottish Medical Journal, 1901, v. viii, p. 121.

31 Lelean: Trans. Medical Society of London, 1902, v. Xxv, p. 259.

${ }^{32}$ Madden, F. C.: Journal of Tropical Medicine, 1901, v. iv, p. 143

33 Rafferty: Medical Record, New York, June 4, 1904.

\section{SOME OBSERVATIONS ON THE OCCURRENCE} OF BROADBENT'S SIGN.*

BY ALICE WELD TAllaNt, M.D., Boston.

The so-called Broadbent's sign, or the systolic retraction of the lower ribs in the left back, has been given so important a place in the diagnosis of adherent pericardium that it is worth while to consider its significance and the frequency of its occurrence.

In 1895, Walter Broadbent ${ }^{1}$ published a report of four cases diagnosed as adherent pericardium, in all of which there was "visible retraction, synchronous with the cardiac systole, of the left back in the region of the eleventh and twelfth ribs; in three, also, systolic retraction of less degree in the same region of the right back." Although he states that this sign had long been pointed out by Sir William Broadbent, he refers to it in the title of his article as "an unpublished physical sign," and I have found no reference to it before 1895.

A year later, in 1896, Dr. John F. H. Broadbent ${ }^{2}$ published his monograph on "Adherent Pericardium." He takes up this point much more in detail, and it is with his name that the sign is associated in most of the textbooks. In his own words, " a most important sign of adherent pericardium " is " a marked systolic retraction of some of the lower ribs on the lateral or posterior aspect of the thorax," which he further describes as "a tug on the false ribs during the cardiac systole, and a sharp rebound during diastole, which can be felt as well as seen when the hand is laid flat on the chest wall at the spot." The phenomenon is due, in his opinion, to adhesions of the pericardium to the muscular parts of the diaphragm, which are dragged upward and inward with the heart's contraction, thereby

* From Dr. Richard C. Cabot's clinic at the Massachusetts General Hospital. 